have had special training) in preventive child care. They dispense vitamins and cheap baby milk. Most provide a sociable clinic atmosphere. All of these features are steadily being reproduced within general practice. In particular there is no reason why milk and vitamins have to be provided exclusively from clinics. Furthermore the claim that clinics are geographically more accessible is unsupported by the evidence. GP premises are more numerous and more widely distributed in the community.

The question now is not whether general practice can or should provide primary preventive care for children, but how quickly it can be done. ${ }^{20}$ If some GPs are unable or unwilling to provide the service, CMOs could be invited to carry out these tasks with access to the practice records and premises. Such a move would foster integration, and might provide better career opportunities for CMOs. ${ }^{21}$

This will allow consultant community paediatricians to concentrate on supporting PHCTs with advice, training, and suitable reporting systems, while accepting responsibility for school health services and the community based services for children with special needs. The clinics, which are at best an expensive anachronism dispensing milk, vitamins, and condoms, and at worst a source of conflicting advice and wasteful duplication, could then be sold-probably to GPs who would upgrade them attractively as they have done so successfully with their own premises! It may be sensible to retain a few clinics to provide secondary paediatric care for those children who are better assessed and treated in a community setting, for example cases of child abuse.

For too long the clinics have been maintained on the grounds that GPs are not ready. It is time we placed our resources and faith in comprehensive primary health care based on general practice. This is essential for the future of our children.
I am indebred to Mrs Linda Redpath who prepared the manuscript.

1 Department of Health and Social Security. National Health Service. General medical and pharmaceutical regulations 1974 Terms of service, para 13. London: Department of Health and Social Security, 1974.

2 Brown AM, Jachuck SJ, Walters F, van Zwanenberg TD. The future of general practice in Newcastle upon Tyne. Lancet 1986;i:370-1.

3 van Zwanenberg TD. Primary health care in Newcastle upon Tyme. A report on the GP facilitator project. Newcastle upon Tyne: Newcastle Local Medical Committee, 1989.

4 British Medical Association. Charter for the family doctor service. London: BMA, 1965.

5 The Health Departments of Great Britain. General practice in the National Health Service. The 1990 contract. London: The Health Departments of Great Britain, 1989.

6 Freer CB. Geriatric screening: a reappraisal of preventive strategies in the care of the elderly. $\mathcal{F} R$ Coll Gen Pract 1985;35:288-90.

7 Secretaries of State for Social Services, Wales, Northern Ireland and Scotland. Primary health care: an agenda for discussion. London: HMSO, 1986. (Cmnd 9771.)

8 Committee on Child Health Services. Fit for the future. London: HMSO, 1976. (Court report.) (Cmnd 6680.)

9 World Health Organisation. Primary health care. Geneva: WHO/UNESCO, 1978. (Health for all series No 1.)

10 Department of Health and Social Security. Annual report 1974. London: HMSO, 1974.

11 Jarman B, Cumberlege J. Developing primary health care. BM7 1987;294:1005-8.

12 MacFarlane A, Pillay U. Who does what, and how much in pre-school child health services in England? $B M \mathcal{F}$ 1984;289:851-2.

13 World Health Organisation European Working Group Today's health-tomorrow's wealth, new perspectives in prevention in childhood. (Summary report, Kiev, 21-25 October 1985.) Geneva: WHO, 1985. (ICP/MCH 102/M O4 (5) 698 IF.)

14 Hall DMB, ed. Health for all children. Oxford: Oxford University Press, 1989.

15 Potrykus C. A threat to effective child health surveillance? Health Visitor 1989;62:207-9.

16 Colver AF, Steiner $H$. Health surveillance of preschool children. BMF 1986;293:258-60.

17 Marsh BN, Russell D, Russell IT. Is paediatrics safe in general practitioners' hands? A study in the north of England. $f R$ Coll Gen Pract 1989;39:138-41.

18 Bryant G. Preventive health care for pre-school children or health surveillance. Child Care Health Dev 1986;12: or health

19 Hart JT. Community general practitioners. BMF 1984;288:1670-3.

20 Pereira Gray DJ. Transfer of responsibility for child health Update 1986:1131-4.

21 Waine $C$. Towards a comprehensive child health service. $\mathcal{F} R$ Coll Gen Pract 1986;36:299.

\title{
Child health clinics
}

\section{Kevin Bellis}

In the last two years one of the major arguments in the National Health Service has been for a reduction in the duplication of services. District health authorities which are euphemistically 'a little short on cash' look towards reducing their services and transferring the cost to another agency, often with the lame excuse that this agency can 'do it better'.

Who makes those decisions about the quality of the service and on what criteria? What may be perceived as 'duplication' by managers and doctors may similarly be viewed as 'choice' by patients or community health councils. There is usually a tendency in such circumstances for professionals to assume that they know what is best for users, often without asking. It is important, therefore, to scotch the myth held by some general practitioners (GPs) that the Court report recommendations said that they are the mainstay of child health surveillance. ${ }^{1}$ In my view there are three key participants in ensuring good child health surveillance, these being the parent(s), health visitors, and doctors. ${ }^{2}$

I cited the issue of choice as one of the key elements of the argument in favour of child health clinics. Why do users of child health services prefer clinics run by the district health authority? On a visit to a local clinic I asked a mother why she brought her child to this clinic rather than taking her baby to her local GP run child health clinic. The answer was simple and direct 'You go to the doctor when you're sick, my bairn's not sick'. Clinics in Newcastle are linked to the notion of health. If GPs are to succeed in providing clinics capable of matching those provided by the district health authority 
they must become more adept at giving patients information about their services and in involving them as equal partners in health care.

In most child health clinics patients appear to be much more involved and engaged. The clinics meet other health needs not merely connected with sickness. Brighton Community Health Council commented in a report in 1984 'At almost all clinics in the Brighton Health District parents are able to purchase baby milk and vitamins following advice from the health visitor'. ${ }^{3}$ Contrast the following descriptions of child health clinics 'Perhaps the ideal clinic is exemplified by Conway Court in Hove. This is a purpose built clinic .... There are two voluntary helpers in addition to the paid staff . . . . able to offer development checks as well as immunisation. The clinic is open at other times during the week for health education, cytology clinics, stroke clubs, parentcraft classes, post-natal support groups and the screening of school age children'3 with the following comments from a staff study day in Newcastle: 'consumers' feel like 'people' at child health clinics and part of the general population. At GP clinics it is very much medical and illness orientated. Consumers suddenly act out the 'patient' role when surrounded by telephones ringing, receptionists bleeping doctors, and doling out repeat prescriptions to unsteady elderly patients who haphazardly negotiate the worn out toys scattered around the waiting room (study morning for community doctors, Newcastle upon Tyne, March 1990). I have no doubt this is a slightly cynical view but it is significant that it came from a group of health care professionals rather than users of the service.

Parents and children prefer to attend child health clinics because of the wider variety of services that are offered. None of these services appear to be more highly favoured alone than any of the others, for example the provision of welfare foods and milk. ${ }^{4}$ The combination of space to park expensive buggies, the provision of health information, and peer support, however, seem to make child health clinics a preferred option.

One of the major reasons that is given to community health councils for retaining a clinic is its accessibility to mothers and babies from the local community. In most studies the majority of mothers choose to walk to the clinic. A survey by Aylesbury Vale Community Health Council showed that $66 \%$ of the clinic attenders surveyed lived less than a mile from the clinic and $51 \%$ of them walked to the clinic. One in three of the mothers brought at least one or more children with them. ${ }^{5}$ The same trend appeared in responses to questions to clinic users in Newcastle, which seems to represent a degree of correlation between clinics in both rural and urban settings. Mothers that we spoke to in a clinic in Fenham in Newcastle said that they preferred to go to their local clinic. A number of mothers had moved into Fenham from other parts of the city and had swapped child health clinics but had not changed their GP to one in a closer location to their new home. The problem is exacerbated by the fact that some
GPs in Newcastle refuse to agree to practice boundaries for their patients. Mothers also cited the timing of the clinic and the lack of an appointment system as being preferable to them than those provided by local GPs. The fact that the clinic ran in the early part of the afternoon meant that mothers could prepare food, take their child to the clinic, and then collect an older child from school. The fact that the clinic worked efficiently meant that mothers liked the 'drop in' style and could allocate enough time for a visit. Many commented that their GPs could not provide such a service due to the pressures of overrunning surgeries, emergencies, and so on or else the GP had instituted an appointment system which meant that both parents and doctors felt obliged to abide by time constraints on appointments. The effect of this on users was highlighted in a recent survey by Which? magazine that said that $89 \%$ of patients felt that doctors should spend more time listening to patients. ${ }^{6}$

The question also has to be asked about the equitable distribution of child health services across a city or health authority area. It is quite obvious that the level of need in terms of health or sickness will vary. Could all users in a city like Newcastle expect the same quality of service for their children from GPs wherever they live? I recognise that there are a large number of extremely dedicated and hard working GPs located in inner city areas providing an excellent service, but the rules controlling access to their lists means that they often become victims of their own success as mothers and children rush to join their practice. What choice and quality is there for those who are not lucky enough to gain access to such care? The potential for not finding and intervening in health risks in children in areas of high health deprivation is appalling. As independent contractors some GPs seem to hold a different view of the delivery of necessary health care. In Newcastle the community health council recently agreed to the closure of an inadequate building that was being used for a child health clinic on the proviso that the same clinic would be reprovided in a local GP's surgery with superior premises adjacent to an area with a number of young families. Some members of the local medical committee have questioned the desirability of this, presumably in case it unfairly draws attenders to the GP's list for other services. Such concern over competition that improves the delivery of health services can only be to the detriment of patients. The nature of the contract between the GP and the family health service authority/family practitioner committee (FHSA/FPC) make it difficult for any outside body, such as the community health council or community groups, to apply pressure to ensure needs are met. The situation becomes a little easier in dealing with the district health authority provision where decisions have to be discussed and consulted upon and where users have a variety of mechanisms at their disposal to ensure that they are heard.

One of the concerns that only a few parents have dared to mention is the relationship between GPs and patients in cases of suspected 
child abuse. The situation is fraught with dangers for the child, GP, and both parents. What happens to the doctor/patient relationship when the 'family doctor' suspects that abuse is taking place. How skilled are all GPs at detection? I would suggest that parents who suspect that their child is being abused may prefer their suspicions allayed or confirmed by an 'external specialist' whom they can trust. Such cases are likely to be extreme but they do highlight the issue of the skills that clinic staff have that are built up by specialisation and experience. A number of professionals have concerns over the ability of GPs to provide an effective service that is of a high quality. A number of commentators have pointed out that large scale surveillance by GPs may be a waste of time in view of their workload, which GPs remind us is increasing with the new contract. Some have gone even further in terms of commenting on the quality of service that is offered. ${ }^{7}$ 'The statement in the Royal College of General Practitioner's report that "we have no doubt that from the point of view of children the immediate start of a comprehensive system of regular child examination through general practice across the country as a whole can be provided by general practitioners trained as they are now"8 is one which has to be questioned."7

Further evidence of the GPs lack of skills were highlighted in a survey in the Northern region. Only $52 \%$ of the GPs surveyed had done a six month residential paediatric job and only 9\% had the diploma in child health. As if these figures were not disconcerting enough in terms of expertise, only $27 \%$ had done a residential paediatric refresher course in the last five years. ${ }^{9}$ Such figures should be disturbing to health care professionals, but how are lay people to obtain such information and then make an informed choice about the most effective provider of screening facilities for their child?

There must also be concern over the ability of parents to seek redress in the event of a mistake being made in assessing their child's health. Community health councils have long held the view that an effective complaints mechanism is a useful quality assurance tool to ensure that patients' needs are met and that the service can be improved. The present GP/FHSA/FPC system means that a GPs clinical judgment cannot be questioned, by a patient, except perhaps through the informal complaints procedure. The importance of an effective complaint system can only be endorsed from the following response of a GP. 'The message of the course was to listen to parents and never dismiss their fears. Aileen Tyler, mother of a growth retarded child, who was ignored by her GP for years, had us all squirming in our seats'. ${ }^{10}$ The GP and FHSA/FPC complaint system does not compare with the district health authority complaint's procedure on clinical issues where second opinions can be sought and full investigations undertaken into the type of care given, even amounting to a review by consultants from outside the region. Such a safeguard is a reassurance to parents and children alike. There are also issues such as the premises being open to inspection and scrutiny by the community health council, which is not an option for GP provided services. Some GPs are wary of user involvement in record keeping with patient held notes and so on. Only a few GPs provide such services, which are often provided as a matter of course in the district health authority clinics.

Finally, there is the matter of the staff who support doctors in providing child health clinics. Health visitors provide much of the care in both types of clinics but those based in child health clinics can draw on support from a wide range of colleagues and professions. I would add hastily that this is not to denigrate the work done by health visitors in primary health care teams, but not all GPs seem to be able to collaborate either equitably nor as well as they suspect with the health visitors in their practice. ${ }^{9}$ Nor do all GPs collaborate well with other agencies. It is worth bearing in mind that the Black report listed accidents and poverty as the two main determinants of childhood morbidity and mortality. ${ }^{11}$ Where clinics integrate into communities it provides a better focus for an intersectorial problem solving approach to improve the chances of better child health system. The ability of GPs to meet all the requirements of their new contract and to maintain a high quality of service in all areas of service delivery is open to question and has been highlighted by GPs themselves. The last thing that users want is a reduction in choice where a service is foisted onto them which is in the interests of GPs' salaries rather than patient needs.

Clinics provide better services for child health services because they have the potential to be an integral part of the communities they serve and can develop a health rather than illness orientation. The staff and volunteers working in them are often local people who can pass on and respond to local information much more effectively than the majority of GPs. Clinics have space and time to treat parents and children as people rather than patients and perhaps most importantly of all, clinics can draw on extra resources, both cash and staff, in a flexible way to meet changes in need as long as they are run by the health authority. In terms of consumer preference clinics seem to have advantages that make the GP alternatives pale in comparison.

1 Committee on Child Health Services. Fit for the future. London: HMSO, 1976. (Court report.) (Cmnd 6680.)

Smith A, Jacobson B, eds. The nation's health - a strategy for the 1990s. London: The King's Fund, 1988.

3 Brighton Community Health Council. Report on a survey of child health clinics in the Brighton health district. Brighton: Brighton Community Health Council, 1984

4 Husain M. Parents' attitudes to a child clinic. Health Visitor 1990;63:84.

5 Aylesbury Vale Community Health Council. The views of users of child health clinics. Aylesbury: Aylesbury Vale Community Health Council, 1989.

6 Anonymous. You and your GP. Which? 1989 October.

7 Bain J. Developmental screening for children: is it worthwhile? f R Coll Gen Pract 1989;39:133-4.

8 Report of a working party appointed by the council of the Royal College of General Practitioners. Healthier childrenthinking prevention. London: Royal College of General Practitioners, 1982. (Report from general practice No 22.)

9 Marsh BN, Russell D, Russell IT. Is paediatrics safe in general practitioners' hands? A study in the north of England. $\mathcal{F}$ $R$ Coll Gen Pract 1989;39:138-41.

10 Robinson $A$. Total confusion over the value and definition of child surveillance. Pulse 1990 Jan 13.

11 Townsend $\mathrm{P}$, Davidson $\mathrm{N}$, eds. Inequalities in health: the Black report and the health divide. London: Penguin, 1988: 118-21. 